\title{
LA ZONA DE INTEGRACIÓN HEMISFÉRICAY Y MERCOSUR: UN CASO PARA ANALIZAR CON RIGOR
}

\author{
RAÚL QUEJADA PEREZ \\ Profesor \\ Facultad de Ciencias Económicas \\ Universidad de Cartagena
}

\section{GENERALIDADES}

L

a evolución dinámica de los mercados externos y sus exigencias actuales requieren la implementación de extrategias orientadas a materializar procesos de integración en el ámbito internacional, cuyo propósito básico debe favorecer las actividades productivas de bienes y servicios con posibilidades futuras de exportación. La btención de mejores resultados se reflejará en aquellos sectores y actividades dispuestos a enfrentar los nuevos desafios tecnológicos, competitivos y de glabalización presentes en el escenario internacional vigente.

La estrategia integracionista en los países de América Latina y el Caribe, se convierte en un marco ineludible para responder a las nuevas circunstancias del entorno mundial; es por ello, que los diversos acuerdos de integración avanzan hacia facetas mas evolucionadas del comercio preferencial y además se gestan nuevos pactos con claras connotaciones de regionalismo abierto apuntando a un bloque hemisférico proyectado al próximo milenio.

Ante la perspectiva del regionalismo abierto ${ }^{1}$, las preferencias tienden a extenderse entre los diferentes acuerdos generándose un mayor clima de

\footnotetext{
${ }^{1} \mathrm{De}$ acuerdo a la Cepal, se define como el proceso que surge de conciliar la interdependencia de acuerdos especiales de carácter preferencial y aquella impulsada básicamente por las señales del mercado, resultantes de la liberalización en general.
} 
cooperación y fortalecimiento de sectores claves entre países signatarios. En la actualidad, se dispone de bases sólidas en lo relacionado con el comercio preferencial latinoamericano, situación ésta que debe conducir al establecimiento de directrices que compatibilicen todo tipo de acuerdos bilaterales y multilaterales en el hemisferio.

\section{BENEFICIOS POTENCIALES DE UNA ZONA DE INTEGRACIÓN HEMISFÉRICA.}

Se prevee que la conformación de una zona de integración regional latinoamericana, traerá consigo considerables ventajas sobre la actividad comercial, financiera $y$ empresarial. Entre las mas importantes se destacan:

- Mejoramiento de los flujos comerciales al interior del continente, lo que influiría positivamente en la especialización productiva y abaratamiento de bienes para los colombianos.

- Aumento de posibilidades en lo concerniente al alcance de mayores economías de escala, eficiencia en la producción e incremento en la competitividad externa.
- Viabilidad de armonizar y homologar normas y procedimientos comerciales, generando un escenario propicio a la clase empresarial que les permita una mejor inserción de sus productos en los mercados.

- Facilitar el acceso a la innovación y transferencia tecnológica entre los países del hemisferio.

- Permitir la libre movilidad de capitales en los países de la región, con la finalidad de garantizar inversiones permanentes e incremento de los flujos comerciales interregionales y extraregionales.

\section{MARCO GENERAL.}

Entre las causas fundamentales de la creación del acuerdo Mercosur, merecen mencionarse: Establecimiento de la democracia de los países de Sur América, la intencionalidad de apertura de sus mercados al mundo y la desregulación y privatización de las economías. Lo anterior contribuyó a la creación del mercado común del sur (1991) constituído por: Argentina, Brasil, Paraguay y Uruguay.

Mercosur, no obstante de constituirse en uno de los acuerdos de integración más recientes, ha 
tenido una dinámica importante como mercado regional atractivo, reflejado esto en la incorporación de nuevos miembros, tales como: Bolivia (1995), Chile (1995), Pacto Andino y Unión Europea, entre otros.

Es importante anotar, que las negociaciones de una zona de libre comercio Grupo Andino-Mercosur, se visualiza por parte de los entendidos en la materia, como el proceso de integración más destacable al que han enfrentado los socios andinos en su existencia como grupo de integración. Este acuerdo tiene implícitos riesgos y oportunidades, mas aún por el mayor grado de desarrollo relativo que presentan Brasil y Argentina frente a los países que conforman el Pacto Andino.

\section{OBJETIVOS BÁSICOS DEL ACUERDO.}

- Ampliación de mercados para países miembros.

- Libre circulación de bienes, servicios y factores de producción en la subregión.

- Creación gradual e integral del arancel externo común.

Generación de una política comercial conjunta y la coordinación de estrategias macroeconómicas sectoriales.

\section{IMPORTANCIA DE MERCOSUR EN LA INTEGRACIÓN HEMISFÉRICA.}

\section{CUADRO No. 1}

\begin{tabular}{|l|r|r|rr|r|}
\hline Países & $\begin{array}{l}\text { Poblac. } \\
\text { en Mill. }\end{array}$ & $\begin{array}{l}\text { Partic } \\
\%\end{array}$ & $\begin{array}{l}\text { PIB } \\
\text { Mill. } \\
\text { \$US }\end{array}$ & $\begin{array}{c}\text { en } \\
\text { c } \\
\%\end{array}$ \\
\hline Argentina & 34.293 & 17 & 270800 & 23 \\
\hline Brasil & 160.737 & 79 & 886300 & 74 \\
\hline Paraguay & 5.358 & 3 & 15400 & 1 \\
\hline Uruguay & 3.423 & 1 & 23000 & 2 \\
\hline $\begin{array}{l}\text { Total } \\
\text { Mercosur }\end{array}$ & 203.811 & 100 & 1196600 & 100 \\
\hline
\end{tabular}

Mercosur, es un acuerdo clave y fundamental con miras a la conformación del ALCA 2005, sus países miembros: Argentina, Brasil, Paraguay y Uruguay constituyen un bloque económico sólido representativo. "El producto interno bruto participa con un $70 \%$ en el total de América del Sur, es decir, unas doce veces la producción colombiana o la décima parte de la economía de los Estados Unidos y más del doble que la del Grupo Andino"2

El cuadro No. 1 nos muestra el gran peso e importancia que tiene Brasil en la subregión, situación reflejada tanto en población como en el producto interno bruto (74 y $79 \%$ respectivamente), distanciado considerablemente de Argentina (17 y $23 \%$ ). Uruguay y Paraguay por el

\footnotetext{
${ }^{2}$ Cumbre ministerial de Comercio y Foro empresarial de las Américas, Revista El Exportador Latinoamericano No. 105.
} 
contrario, presentan una participación marginal al interior del grupo (1 y 3\%-2 y $1 \%$ ) para la población y el PIB respectivamente.

\section{ACTIVIDAD COMERCIAL.}

El ámbito comercial representa para Mercosur uno de los principales soportes de integración en el contexto latinoamericano, en este orden de ideas y como se ha expresado son Brasil y Argentina los países miembros más representativos, evidenciándose su marcado liderazgo intragrupo al igual que en las negociaciones extraregionales. Esto obedece a su mayor grado de desarrollo relativo e industrial frente al resto de países signatarios del Acuerdo.

\section{BRASIL.}

Cuadro No. 2

TASA DE PARTICIPACIÓN DE LAS EXPORTACIONES POR SECTORES

(En Porcentajes)

\begin{tabular}{|c|c|c|c|c|c|}
\hline Años & $\begin{array}{c}\text { Agri- } \\
\text { cultu } \\
\text { r }\end{array}$ & $\begin{array}{c}\text { Mine } \\
\text { ria }\end{array}$ & $\begin{array}{c}\text { Agro } \\
\text { ind. }\end{array}$ & $\begin{array}{c}\text { Indus } \\
\text { tia }\end{array}$ & Total \\
\hline 1992 & 11 & 13 & 15 & 61 & 100 \\
\hline 1993 & 11 & 12 & 14 & 63 & 100 \\
\hline 1994 & 13 & 11 & 16 & 60 & 100 \\
\hline 1995 & 12 & 12 & 17 & 59 & 100 \\
\hline $1996^{\star}$ & 12 & 13 & 15 & 60 & 100 \\
\hline
\end{tabular}

Fuente: Ministerio de Comercio Exterior de Colombia, 1996.

Cálculos del autor con base en la información de Exportaciones e Importaciones tomados de la fuente señalada.

*CEPAL, información preliminar.

En lo referente al aspecto comercial y de acuerdo a lo observado en los cuadros Nos. 2 y 3 , las exportaciones e importaciones de Brasil por sectores tienen un patrón de especialización industrial, ya que la tasa de participación de ésta es del 60 y $70 \%$ aproximadamente y en menor grado participan los otros sectores (agricultura, minería y agroindustria).

Cuadro No. 3

TASA DE PARTICIPACIÓN DE LAS IMPORTACIONES POR SECTORES (En Porcentajes)

\begin{tabular}{|c|c|c|c|c|c|}
\hline Años & $\begin{array}{c}\text { Agri- } \\
\text { cultu } \\
\text { r }\end{array}$ & $\begin{array}{c}\text { Mine } \\
\text { ria }\end{array}$ & $\begin{array}{c}\text { Agro } \\
\text { ind. }\end{array}$ & $\begin{array}{c}\text { Indus } \\
\text { tia }\end{array}$ & Total \\
\hline 1992 & 7 & 24 & 5 & 64 & 100 \\
\hline 1993 & 7 & 15 & 7 & 71 & 100 \\
\hline 1994 & 6 & 12 & 7 & 73 & 100 \\
\hline 1995 & 5 & 10 & 8 & 77 & 100 \\
\hline $1996^{*}$ & 6 & 11 & 8 & 75 & 100 \\
\hline
\end{tabular}

Fuente: Ministerio de Comercio Exterior de Colombia, 1996.

Cálculos del autor con base en la información de Exportaciones e Importaciones tomados de la fuente señalada.

*CEPAL, información preliminar.

\section{ARGENTINA.}

\section{Cuadro No. 4}

TASA DE PARTICIPACIÓN DE LAS EXPORTACIONES POR SECTORES (En Porcentajes)

\begin{tabular}{|c|c|c|c|c|c|}
\hline Años & $\begin{array}{c}\text { Agri- } \\
\text { cultu } \\
\text { r }\end{array}$ & $\begin{array}{c}\text { Mine } \\
\text { ría }\end{array}$ & $\begin{array}{c}\text { Agro } \\
\text { ind. }\end{array}$ & $\begin{array}{c}\text { Indus } \\
\text { tia }\end{array}$ & Total \\
\hline 1992 & 30 & 5 & 32 & 33 & 100 \\
\hline 1993 & 27 & 5 & 30 & 38 & 100 \\
\hline 1994 & 25 & 9 & 29 & 37 & 100 \\
\hline 1995 & 24 & 9 & 28 & 39 & 100 \\
\hline $1996^{\star}$ & 25 & 8 & 29 & 38 & 100 \\
\hline
\end{tabular}

Fuente: Ministerio de Comercio Exterior de Colombia, 1996.

Cálculos del autor con base en la información de Exportaciones e Importaciones tomados de la fuente señalada.

*CEPAL, información preliminar.

Argentina, es considerado el socio más importante de Brasil al interior 
Por último se resalta el hecho de la presencia de Brasil y Argentina en el mercado común del sur (Mercosur), lo que confiere a este grupo una importancia notable en los planos social y político en el marco latinoamericano, constituyéndose en motivo de atracción para que otras naciones de América Latina y el Caribe se vinculen activamente a esta iniciativa, no obstante de ser uno de los procesos de integración más recientes en Latinoamérica.

\section{BIBLIOGRAFIA}

CEPAL, 1992. "Influencias para la integración latinoamericana". Santiago de Chile.

CEPAL, 1994. "'La coordinación de las políticas macroeconómicas en el contexto de la integración latinoamericana: Una primera aproximación para el caso de la integración de América Latina y el Caribe". Santiago de Chile.

Economía Abierta (1996). Revista Ministerio de Comercio Exterior de Colombia.

GARAY, Luis Jorge y DEVLIN, Robert. "Coyuntura económica (1996) de Miami a Cartagena: Nueve enseñanzas y nueve desafios del ALCA". Págs. 96 y 97.
** Economista. Egresado de la Universidad de Cartagena. Docente de la Facultad de Ciencias Económicas, Universidad de Cartagena. Adscrito al Departamento de Investigaciones Económicas y Sociales, DIES. Con Postgrado en Política Económica, Universidad Nacional de Colombia. 
constituyen en complementarios a la luz de las negociaciones extraregionales.

Los cuadros Nos. 4 y 5 , muestran para las tasas de importaciones y exportaciones de Argentina, una importancia sectorial más equitativa que su socio Brasil, ya que los sectores agricultura, agroindustria e industria representan un $95 \%$ del total de las exportaciones. Para el caso de las importaciones es la industria del sector de mayor dinámica (72\% aproximadamente) seguido por la agricultura (18\%) y los otros sectores que reflejan una reducida participación $(10 \%)$.

\section{Cuadro No. 5}

TASA DE PARTICIPACIÓN DE LAS IMPORTACIONES POR SECTORES (En Porcentajes)

\begin{tabular}{|c|c|c|c|c|c|}
\hline Años & $\begin{array}{c}\text { Agri- } \\
\text { cultu } \\
\text { r }\end{array}$ & $\begin{array}{c}\text { Mine } \\
\text { ría }\end{array}$ & $\begin{array}{c}\text { Agro } \\
\text { ind. }\end{array}$ & $\begin{array}{c}\text { Indus } \\
\text { tia }\end{array}$ & Total \\
\hline 1992 & 7 & 24 & 5 & 64 & 100 \\
\hline 1993 & 7 & 15 & 7 & 71 & 100 \\
\hline 1994 & 6 & 12 & 7 & 73 & 100 \\
\hline 1995 & 5 & 10 & 8 & 77 & 100 \\
\hline $1996^{\star}$ & 6 & 11 & 8 & 75 & 100 \\
\hline
\end{tabular}

Fuente: Ministerio de Comercio Exterior de Colombia, 1996.

Cálculos del autor con base en la información de Exportaciones e Importaciones tomados de la fuente señalada.

*CEPAI, información preliminar.

\section{URUGUAY - PARAGUAY}

Muy a pesar que Uruguay y Paraguay, poseen una participación marginal intragrupo del 3\% (Ver
Cuadro No. 6

\section{ACTIVIDAD COMERCIAL DE URUGUAY}

En millones de dólares

\begin{tabular}{|c|c|c|c|c|c|}
\hline $\begin{array}{l}\text { AÑOS/AGREG. } \\
\text { CCLALES. }\end{array}$ & 1991 & 1992 & 1993 & 1994 & 1995 \\
\hline EXPORTACIÓN & 1596 & 1703 & 1645 & 1913 & 1889.2 \\
\hline IMPORTACIÓN & 1622 & 2061 & 2324 & 2773 & 2868.7 \\
\hline CCIO. GLOBAL & 3218 & 3764 & 3969 & 4686 & 4757.9 \\
\hline
\end{tabular}

Cuadro No. 7

\section{ACTIVIDAD COMERCIAL DE PARAGUAY}

En millones de dólares

\begin{tabular}{|c|c|c|c|c|c|}
\hline $\begin{array}{l}\text { AÑOS/AGREG. } \\
\text { CCIALES. }\end{array}$ & 1991 & 1992 & 1993 & 1994 & 1995 \\
\hline EXPORTACIÓN & 737 & 657 & 695 & 819 & 831 \\
\hline IMPORTACIÓN & 1311 & 1237 & 1473 & 2049 & 2550 \\
\hline CCIO. GLOBAL & 2048 & 1894 & 2168 & 2868 & 3381 \\
\hline
\end{tabular}

Cuadro No. 1), presentan un clima excepcional para la inversión extranjera destacando principalmente su ubicación estratégica, estabilidad económica y además una producción diversificada fundamentalmente en productos agroindustriales e industriales. agrícolas,

Con relación a las actividades comerciales, se observa que la dinámica de su comercio global no es muy significativa, ya que para el período en estudio (Ver Cuadros Nos. 6 y 7), se refleja un comportamiento muy diferente que su comercio en comparación con el resto de países de la subregión. 